\title{
Técnicas para estimativa da digestibilidade e produção microbiana em bovinos $^{1}$
}

\author{
Marcia Dias ${ }^{2}$, Maria Ignez Leão ${ }^{3}$, Edenio Detmann ${ }^{3}$, Sebastião de Campos Valadares Filho ${ }^{3}$, \\ Angela Maria de Vasconcelos ${ }^{2}$, Shirley Motta de Souza ${ }^{2}$, Mário Fonseca Paulino ${ }^{3}$, Tássio \\ Bonomo Murça ${ }^{4}$
}

\footnotetext{
${ }^{1}$ Pesquisa financiada pelo CNPq.

2 Pós-graduação em Zootecnia - UFV, Viçosa - MG

${ }^{3}$ Departamento de Zootecnia - UFV, Viçosa - MG.

${ }^{4}$ Curso de graduação em Zootecnia - UFV, Viçosa - MG.
}

RESUMO - Objetivou-se avaliar estimativas de digestibilidade e de produção microbiana utilizando fibra em detergente neutro e ácido indigestível (FDNi e FDAi, respectivamente) e comparar a produção microbiana estimada pelos métodos das bases purinas e excreção urinária de derivados de purinas. Utilizaram-se quatro novilhas Holandês-Zebu com peso vivo médio inicial de $220 \mathrm{~kg}$, fistuladas no rúmen e no íleo, mantidas em regime de confinamento com dieta à base de feno de capim-Tifton (Cynodon spp.), oferecido ad libitum, e $1 \mathrm{~kg}$ de concentrado (27\% PB). O experimento durou 60 dias: sete de adaptação à dieta (antes do primeiro período), três períodos experimentais de 15 dias cada e quatro dias de intervalo entre os períodos. Foram realizadas coleta total de fezes, coleta de digesta omasal e ileal, coleta de conteúdo ruminal para isolamento bacteriano e coleta de amostra spot de urina. Para determinação dos fluxos de digesta omasal e ileal, foram utilizados como indicadores a FDNi e a FDAi. As condições do rúmen foram favoráveis à produção microbiana, com valores de $\mathrm{pH}$ e $\mathrm{N}-\mathrm{NH}_{3}$ de 6,7 a 6,9 e de 10,3 a 14,1 $\mathrm{mg} / \mathrm{dL}$, respectivamente. A recuperação da FDAi não diferiu de $100 \%$ e produziu estimativas similares à excreção fecal e à digestibilidade total, quando comparada à coleta total de fezes, diferentemente de FDNi. As estimativas da produção microbiana via quantificação de derivados de purinas em amostras spot de urina não foram similares às obtidas por procedimentos invasivos via fluxo de matéria microbiana omasal. Assim, recomenda-se utilização de FDAi para estimativas de digestibilidade total e parcial e, para a produção microbiana, a excreção urinária dos derivados de purinas.

Palavras-chave: capim-Tifton, derivados de purina, fibra em detergente ácido, fibra em detergente neutro, indicadores, omaso

\section{Techniques for estimate of digestion and microbial production in bovine}

\begin{abstract}
The objective was to evaluate the estimate of digestion and microbial production by using indigestible neutral and acid detergent fiber (iNDF and iADF respectively) and to compare microbial production estimated by purine bases in the omasum and urinary excretion of purine derivatives. Four rumen and ileum fistulated Holstein-Zebu heifers with average initial $220 \mathrm{~kg} \mathrm{LW}$ was maintained in confined regime fed diet based on Tifton (Cynodon spp.) hay, offered ad libitum and $1 \mathrm{~kg}$ of concentrate $(27 \% \mathrm{CP})$. The experiment lasted 60 days: seven for adaptation to the diet (before the first period); three 15 day-experimental periods and four days of interval among periods. Total collection of feces, omasum and ileum digesta sampling, rumen contents sampling for bacterial isolation and sampling of urine spot were performed. For the determination of omasal and ileal flow, iNDF and iADF were used as markers. Rumen enviromment was favourable for microbial growth, showing $\mathrm{pH}$ values between 6.7 to 6.9 and $\mathrm{NH}_{3}-\mathrm{N}$ values from 10.3 to $14.1 \mathrm{mg} / \mathrm{dL}$. Recovery of iADF did not differ from $100 \%$ and produced similar estimation for fecal excretion and total digestion, when compared to total fecal sampling, differently of iNDF. Estimation of microbial production through quantification of purine derivative in urine spot samples was not similar to the obtained by invasive procedure through omasal microbial matter. Thus, it is recommended to use iADF for partial and total digestion estimation and urinary excretion of purine derivative for microbial production estimation.
\end{abstract}

Key Words: tifton bermudagrass hay, purine derivative, acid detergent fiber, neutral detergent fiber, markers, omasum 


\section{Introdução}

O processo de digestão nos ruminantes é o resultado de uma seqüência de eventos que ocorrem em diferentes segmentos do trato digestório. O local de digestão influencia a natureza dos produtos finais absorvidos, a extensão das perdas ocorridas e a resposta produtiva do animal (Merchen et al., 1997). Os estudos de digestão parcial dos nutrientes das dietas são importantes por permitirem quantificar a utilização dos nutrientes nos diferentes compartimentos do trato gastrintestinal, facilitando a avaliação das diferenças existentes entre alimentos (Valadares Filho, 1985).

Entre os indicadores internos, as fibras indigestíveis são as mais utilizadas, tendo sido recomendadas por vários pesquisadores para a estimativa da digestibilidade (Saliba et., 1999; Freitas et al., 2002; Pereira, 2003). Segundo Cochran et al. (1986), a fibra em detergente neutro indigestível (FDNi) e a fibra em detergente ácido indigestível (FDAi) são indicadores com potencial de utilização para a estimativa da digestibilidade. Esses indicadores apresentam a vantagem de ter quantificação mais simples e econômica.

Além do conhecimento do valor nutritivo dos alimentos, atualmente, outro fator importante na nutrição de ruminantes é o conhecimento da produção microbiana. Elevada produção microbiana diminui a necessidade de suplementação com proteína dietética não-degradada no rúmen, o que torna desejável a maximização de sua produção.

A quantidade de compostos nitrogenados microbianos é medida com indicadores microbianos como bases purinas (RNA), ácido 2,6 diaminopimélico (DAPA), ${ }^{35} \mathrm{~S}$ e ${ }^{15} \mathrm{~N}$. Broderick \& Merchen (1992) recomendaram a utilização das bases purinas e ${ }^{15} \mathrm{~N}$. Esses autores, contudo, destacaram que nenhum indicador é totalmente adequado, conseqüentemente, as estimativas obtidas são relativas e não absolutas. Valadares Filho et al. (1990a), comparando o método direto do DAPA e das purinas, concluíram que o método das bases purinas foi adequado para estimar a produção microbiana em ruminantes. Com estes métodos, entretanto, há necessidade da utilização de animais fistulados, havendo interesse crescente no desenvolvimento de técnicas nãoinvasivas (Susmel et al., 1994).

Entre as técnicas de estimativa de compostos microbianos, a que se baseia na excreção de derivados de purina na urina é menos invasiva, por não necessitar que os animais experimentais sejam preparados cirurgicamente. Nesta técnica, assume-se que a absorção de purinas está condicionada à quantidade de proteína microbiana, que pode ser estimada a partir da excreção urinária dos derivados de purinas: alantoína, ácido úrico, xantina e hipoxantina (Giesecke et al., 1994).
Embora a técnica de derivados de purina na urina não seja invasiva, ela necessita de uma estimativa da produção total de urina. Em razão de a excreção de creatinina ser relativamente constante em função do peso vivo e ter pequena ou nenhuma influência de fatores dietéticos (Valadares et al., 1997), esta pode ser usada como indicador da produção urinária. Isto possibilita a estimativa da excreção dos derivados de purinas sem a necessidade de coleta total de urina, pela utilização de única amostra, denominada spot (Valadares et al., 1999; Valadares Filho et al., 2001; Leão, 2002; Rennó et al., 2003). Em vários trabalhos verifica-se confirmação de que as estimativas obtidas a partir da coleta spot são representativas das excreções de derivados de purinas e da produção de nitrogênio $(\mathrm{N})$ microbiano em ruminantes (Silva et al., 2001; Oliveira et al., 2001; Leão, 2002; Chizzotti et al., 2004).

Ao realizar este trabalho, objetivou-se comparar as estimativas da digestibilidade total e parcial de nutrientes e a produção microbiana, utilizando-se como indicadores a fibra em detergente neutro indigestível e fibra em detergente ácido indigestível, e comparar a produção microbiana estimada pelos métodos das bases purinas e da excreção urinária de derivados de purinas.

\section{Material e Métodos}

O experimento foi conduzido no Departamento de Zootecnia do Centro de Ciências Agrárias da Universidade Federal de Viçosa, em Viçosa, Minas Gerais. Foram utilizadas quatro novilhas mestiças Holandês-Zebu, fistuladas no rúmen e no íleo, com peso vivo (PV) médio inicial de $220 \mathrm{~kg}$ e idade de 12 meses, mantidas em baias individuais de alvenaria $\left(3 \mathrm{~m}^{2}\right)$, cobertas, com pisos recobertos com borracha, dotadas de bebedouros automáticos e comedouros.

O arraçoamento foi realizado duas vezes ao dia ( 8 e $16 \mathrm{~h}$ ) e a dieta (Tabela 1) consistia de feno de capimTifton (Cynodon spp.) oferecido ad libitum e $1 \mathrm{~kg}$ de concentrado (Tabela 2).

O experimento teve duração de 60 dias com três períodos experimentais de 15 dias cada (Tabela 3 ). Antes do primeiro período experimental, foi realizada a adaptação dos animais à dieta experimental por sete dias e, entre os períodos, respeitou-se intervalo de quatro dias. As pesagens dos animais foram realizadas ao início e término de cada período experimental.

Para estimativa do fluxo de digesta omasal e ileal, foram utilizados como indicadores a fibra em detergente neutro indigestível (FDNi) e a fibra em detergente ácido indigestível (FDAi). 
Diariamente foram registradas as quantidades de alimentos fornecidos e das sobras de cada animal para estimativa do consumo. Foram coletadas amostras dos alimentos e, todos os dias antes do arraçoamento matinal, amostras de sobras para posteriores análises. Imediatamente após a coleta das sobras, foi feita a pré-secagem em estufa de ventilação forçada a $60^{\circ} \mathrm{C}$, durante 96 horas. Após secas e moídas, foram compostas proporcionalmente, com base no peso seco ao ar, por animal e período, antes de serem armazenadas.

Tabela 1 - Composição dos ingredientes do concentrado da dieta experimental (\% na MS)

\begin{tabular}{lr}
\hline Ingrediente & MS (\%) \\
\hline Farelo de soja & 46,20 \\
Fubá de milho & 47,99 \\
Sal & 1,22 \\
Fosfato bicálcio & 2,47 \\
Calcário & 1,45 \\
Sulfato de amônia & 0,15 \\
Cloreto de potássio $^{\text {Premix mineral }}{ }^{1}$ & 0,44 \\
\hline
\end{tabular}

${ }^{1}$ Sulfato de zinco: $82,24 \%$; sulfato de cobre: $16,45 \%$; sulfato de cobalto: $0,99 \%$ e selenito de sódio: 0,33 .

Tabela 2 - Composição nutricional dos alimentos e do concentrado da dieta experimental (\% na MS)

\begin{tabular}{lcrrr}
\hline Item $^{1}$ & $\begin{array}{c}\text { Feno de } \\
\text { capim-Tifton }\end{array}$ & $\begin{array}{c}\text { Fubá de } \\
\text { milho }\end{array}$ & $\begin{array}{c}\text { Farelo de } \\
\text { soja }\end{array}$ & Concentrado \\
\hline MS & 80,38 & 84,82 & 85,64 & 85,96 \\
MO & 93,98 & 99,12 & 93,48 & 90,75 \\
PB & 12,61 & 8,23 & 50,27 & 27,17 \\
EE & 2,05 & 4,01 & 1,22 & 2,49 \\
CT & 79,32 & 86,88 & 41,99 & 61,09 \\
FDNcp & 76,12 & 37,03 & 18,33 & 26,24 \\
CNF & 3,20 & 49,85 & 23,66 & 34,85 \\
FDA & 50,88 & 18,59 & 16,96 & 21,38 \\
FDNi & 31,66 & 2,48 & 1,88 & 2,06 \\
FDAi & 14,75 & 0,59 & 0,69 & 0,60 \\
\hline
\end{tabular}

${ }^{1} \mathrm{CT}=$ carboidratos totais; CNF = carboidratos não-fibrosos.

Tabela 3 - Cronograma de atividades realizadas em cada período experimental

\begin{tabular}{ll}
\hline Dia & \multicolumn{1}{c}{ Atividade } \\
\hline 1 & Coleta total de fezes \\
$2-4$ & Coleta de digesta omasal \\
5 e 6 & \multicolumn{1}{c}{-} \\
7 & Coleta total de fezes \\
$8-10$ & Coleta de digesta ileal \\
11 e 12 & $\quad$ Coleta total de fezes \\
13 & $\begin{array}{l}\text { Coleta de líquido ruminal para estimativa } \\
\text { de pH e N-NH }\end{array}$ \\
& de urina coleta de amostra spot \\
& Coleta de líquido ruminal para isolamento \\
15 & bacteriano \\
\hline
\end{tabular}

A coleta total de fezes foi realizada por 24 horas, iniciando-se imediatamente antes do arraçoamento matinal. A cada seis horas, a produção fecal obtida pela defecação espontânea de cada animal foi pesada, homogeneizada e amostrado $10 \%$ do peso em matéria natural. Após o período de coleta, foi quantificada a produção fecal total pela soma das quatro pesagens e feita amostra composta das quatros subamostragens.

As coletas de digesta (omasal e ileal) foram realizadas da seguinte forma: no primeiro dia foram feitas antes do arraçoamento matinal ( 0 hora) e 6 horas após; no segundo dia, 2 e 8 horas após o arraçoamento; e no terceiro dia, 4 e 10 horas.

$\mathrm{Na}$ coleta de amostras de digesta omasal, foi utilizado um conjunto de dispositivos que consistiram de um kitassato, um tubo coletor e uma bomba a vácuo conforme técnica descrita por Leão (2002). As amostras de digesta ileal foram coletadas em sacos plásticos adaptados na extremidade do tubo da cânula até que a digesta fluísse normalmente.

As amostras de digesta (omasal e ileal) e de fezes foram congeladas $\left(-20^{\circ} \mathrm{C}\right) \operatorname{logo}$ após a coleta para posterior processamento. Após o descongelamento da digesta omasal, foi feita uma amostra composta por animal e período experimental, para posterior pré-secagem juntamente com as amostras de digesta ileal e de fezes. Todas as amostras foram moídas e armazenadas em frascos para posteriores análises laboratoriais. As amostras de sobras, de digesta ileal e de fezes, após secagem e moagem, foram compostas proporcionalmente, com base no peso seco ao ar, por animal e período, antes de serem armazenadas.

A coleta de digesta ruminal foi realizada quatro horas após a alimentação para isolamento de bactérias, conforme técnica sugerida por Cecava et al. (1990). Para a medição do pH e determinação da concentração de nitrogênio amoniacal $\left(\mathrm{N}-\mathrm{NH}_{3}\right)$ no líquido ruminal, foram realizadas coletas de amostras imediatamente antes e duas, quatro, seis e oito horas após o arraçoamento matinal. $\mathrm{O} \mathrm{pH}$ foi estimado por peagâmetro digital após filtragem em gaze. Posteriormente, amostras de $50 \mathrm{~mL}$ foram acondicionadas em recipientes plásticos contendo $1 \mathrm{~mL}$ de solução de ácido sulfúrico (1:1) e armazenadas em congelador para posterior determinação do $\mathrm{N}-\mathrm{NH}_{3}$, conforme técnica de Ferner (1965), modificada por Vieira (1980).

Para estimativa da produção de proteína microbiana, foram utilizadas as bases purinas como indicador microbiano, cuja quantificação foi realizada de acordo com técnica de Ushida et al. (1985). A coleta spot de urina foi feita após micção espontânea, a partir de um intervalo de quatro horas do arraçoamento matinal. 
As amostras de alimentos, sobras, digesta omasal e ileal e fezes foram submetidas à análise de FDNi e FDAi em sacos Ankon (filter bags F57), por meio de incubação in situ por 240 horas (Lippke et al., 1986), em uma vaca holandesa fistulada no rúmen recebendo dieta à base de silagem de milho. Todas as amostras foram analisadas quanto aos teores de MS, MO, PB e EE, de acordo com técnicas descritas pela AOAC (1990) e fibra em detergente neutro (FDN), pela técnica da autoclavagem (Pell \& Schofield, 1993). Do resíduo da FDN foram determinadas a cinza e a proteína, conforme técnica descrita por AOAC (1990), para obtenção da FDN corrigida para cinzas e proteína (FDNcp).

Foram quantificados em todas as amostras os carboidratos totais (CT), de acordo com a equação: 100 $(\% \mathrm{~PB}+\% \mathrm{EE}+\% \mathrm{MM})$, e os teores de carboidratos nãofibrosos (CNF), pela diferença entre os teores de CT e FDNcp.

Nas amostras de urina foram determinadas as concentrações de creatinina, alantoína e ácido úrico. A análise de creatinina foi realizada pelo método diacetil modificado (kit comercial) e utilizada para o cálculo de estimativa do volume urinário, com base no valor da excreção diária de creatinina (Y, mg $/ \mathrm{kg}$ PV) da equação descrita por Chizotti et al. (2004): $Y=0,9772+0,0250 \times$ PV. O peso vivo utilizado para o cálculo foi o obtido no término de cada período experimental.

As análises de derivados de purinas (alantoína e ácido úrico) foram realizadas pelo método colorimétrico, conforme técnica de Fujihara etal.(1987), modificada por Chen \& Gomes (1992). As purinas microbianas absorvidas (X, mmol/dia) foram calculadas a partir da excreção de derivados de purinas $(\mathrm{Y}, \mathrm{mmol} / \mathrm{dia})$, por intermédio da equação $\mathrm{Y}=0,85 \mathrm{X}$ $+0,385 \mathrm{PV}^{0,75}$, em que 0,85 é a recuperação de purinas absorvidas como derivados de purinas urinários e $0,385 \mathrm{PV}^{0,75}$, a contribuição endógena para a excreção de purina (Verbic et al., 1990). O fluxo intestinal de compostos nitrogenados (N) microbianos (Y, gN/dia) foi calculado em função das purinas microbianas absorvidas (X, mmol/dia), utilizando-se a equação $\mathrm{Y}=(70 \mathrm{X}) /(0,83 \times 0,116 \times 1000)$, em que 70 representa o $\mathrm{N}$ nas purinas ( $\mathrm{mgN} / \mathrm{mmol}) ; 0,83$, a digestibilidade das purinas microbianas; e 0,116, a relação N-RNA:NT nas bactérias (Chen \& Gomes, 1992).

Os dados foram analisados, segundo o modelo:

$$
\mathrm{Y}_{\mathrm{ijk}}=\mu+\mathrm{A}_{\mathrm{i}}+\mathrm{P}_{\mathrm{j}}+\mathrm{e}_{\mathrm{ij}}+\mathrm{I}_{\mathrm{k}}+\varepsilon_{\mathrm{ijk}}
$$

em que $Y_{i j k}$ é a observação da variável referente ao animal i, no período j e com o indicador ou método de estimação de fluxo microbiano $\mathrm{k} ; \mu$, a constante geral; $\mathrm{A}_{\mathrm{i}}$, o efeito relacionado ao animal $\mathrm{i} ; \mathrm{P}_{\mathrm{j}}$, o efeito relacionado ao período $\mathrm{j} ; \mathrm{e}_{\mathrm{ij}}, \mathrm{o}$ efeito residual das parcelas experimentais; $\mathrm{I}_{\mathrm{k}}$, o efeito relacionado ao indicador ou ao método de estimação de fluxo microbiano k; e $\varepsilon_{\mathrm{ijk}}$, o erro aleatório, associado a cada observação, pressuposto NID $\left(0 ; \sigma^{2}\right)$.

Todas as análises estatísticas foram realizadas por intermédio do programa SAS (1999), adotando-se nível de significância de 5\%. Para a comparação das médias de digestibilidade total e parcial, recuperação de indicadores e excreção fecal, foi adotado o teste Tukey $(\alpha=5 \%)$.

\section{Resultados e Discussão}

O consumo de FDNcp foi próximo a 1,2\% PV, valor sugerido por Mertens (1994) como o consumo a partir da qual a ingestão de alimentos é controlada pelo efeito físico (enchimento do rúmen). Vale ressaltar que o consumo de MS expresso em \% PV consiste em importante unidade de mensuração por viabilizar comparação consistente entre experimentos (Tabela 4). O consumo pelos animais observados neste estudo foi de $1,83 \% \mathrm{PV}$, próximo ao observado por Rennó et al. (2004a), de 2,28\% PV, e aos obtidos por Leão et al. (2004), de 2,07\%. Os valores de consumo de MO e FDNcp, expressos em \% PV, também foram próximos àqueles dos experimentos de Leão et al. (2004) e Leão et al. (2005), respectivamente.

Considerando o intervalo de confiança estimado para os indicadores e comparando suas recuperações, a FDAi apresentou melhor recuperação, uma vez que não diferiu $(\mathrm{P}>0,05)$ de $100 \%$ de recuperação e apresentou maior valor $(\mathrm{P}<0,05)$, ao contrário da FDNi, que diferiu $(\mathrm{P}<0,05)$ de $100 \%$ de recuperação. Em razão da baixa recuperação da FDNi, a excreção fecal foi superestimada, enquanto a estimativa a partir da FDAi não diferiu $(\mathrm{P}>0,05)$ da coleta total de fezes. Por causa disso, todos os coeficientes de digestibilidade

Tabela 4 - Consumos médios diários de nutrientes

\begin{tabular}{|c|c|c|}
\hline \multirow[b]{2}{*}{ Nutriente } & \multicolumn{2}{|c|}{ Consumo } \\
\hline & Média & Erro-padrão \\
\hline & \multicolumn{2}{|c|}{$\mathrm{kg} / \mathrm{dia}$} \\
\hline MS & 3,836 & 0,215 \\
\hline MO & 3,581 & 0,201 \\
\hline PB & 0,593 & 0,033 \\
\hline $\mathrm{EE}$ & 0,083 & 0,004 \\
\hline $\mathrm{CT}$ & 2,906 & 0,165 \\
\hline FDNcp & 2,546 & 0,155 \\
\hline \multirow[t]{2}{*}{$\mathrm{CNF}$} & 0,359 & 0,014 \\
\hline & \multicolumn{2}{|c|}{$\mathrm{g} / \mathrm{kg}$ PV } \\
\hline MS & 18,3 & 0,098 \\
\hline $\mathrm{MO}$ & 16,2 & 0,092 \\
\hline FDNcp & 11,9 & 0,070 \\
\hline
\end{tabular}

${ }^{1} \mathrm{CT}$ = carboidratos totais; FDNcp = fibra em detergente neutro corrigida para cinzas e proteína; CNF = carboidratos não-fibrosos 
dos diferentes nutrientes estimados pela FDAi não diferiram $(\mathrm{P}>0,05)$ dos da coleta total, ao passo que os estimados pela FDNi foram subestimados (Tabela 5).

Os resultados observados neste experimento corroboram os observados na literatura, que indicam a utilização da FDAi para estimativa de produção fecal. Saliba et al. (1999) também observaram melhor resultado com a FDAi ao compararem diferentes indicadores com o método de coleta total de fezes. Freitas et al. (2002), comparando a FDNi e a FDAi para estimar a produção fecal e o fluxo duodenal de MS em novilhos confinados, afirmaram que a FDAi pode ser usada para estimar a produção fecal, enquanto a FDNi superestima a produção fecal.

Ítavo et al. (2002), avaliando a utilização da FDNi e FDAi para estimar a produção fecal e a digestiblidade dos nutrientes em bovinos, relataram que a FDNi subestimou a digestiblidade e sugeriram a FDAi como melhor indicador. Zeoula et al. (2002), por sua vez, relataram que a FDAi subestimou a digestibilidade aparente da MS quando comparada à coleta total de fezes e Berchielli et al. (1998, 2000) recomendaram o uso de ambos os indicadores (FDNi e FDAi).

Os únicos nutrientes que apresentaram diferença na digestibilidade ruminal $(\mathrm{P}<0,05)$ em função do indicador utilizado foram a PB e o EE (Tabela 6). Porém, era esperada influência do indicador, como observado na digestibilidade total (Tabela 5), pois a quantificação da excreção fecal é a medida básica para qualquer estudo de digestão. A ausência de diferenças significativas pode decorrer da maior variabilidade dos resultados de digestibilidade parcial em relação à total, devido à dificuldade de se obterem amostras de digestas homogêneas em métodos invasivos.

A digestão ruminal e pós-ruminal da FDN pode ser utilizada como indicação de funcionalidade do indicador. Se o fluxo total da digesta para o duodeno é superestimado, a digestão ruminal da FDN pode ser subestimada e, de forma errônea, grande proporção da FDN será digerida nos intestinos (Titgemeyer, 1997). Como neste experimento, as digestibilidades da FDN e MS foram maiores no rúmen, pode-se inferir que ambos os indicadores estimaram de forma correta os fluxos de MS no omaso. A digestibilidade ruminal, de modo geral, foi inferior às observadas em outros trabalhos utilizando feno de capim-Tifton (Rennó et al., 2004b; Leão et al., 2004). A maior digestão do EE foi a intestinal, porque no ambiente ruminal não há microrganismos capazes de utilizar esse componente como substrato energético.

A digestibilidade intestinal da PB foi, em média, de $56,4 \%$, valor inferior aos $66,0 \%$ descritos por Leão et al. (2004) e aos 60,41\% observados por Rennó et al. (2004b), que também utilizaram feno de capim-tifton como volumoso. A digestibilidade ruminal do EE apresentou valor negativo, indicando síntese de lipídeos microbianos, ao passo que a digestibilidade intestinal dos CT foi superior aos observados por Rennó et al. (2004b) (11,86\%) e Cabral (2002) de $14,12 \%$. A digestibilidade intestinal da FDN no intestino delgado foi, em média, de $9,13 \%$, valor semelhante aos $8,11 \%$ observados por Leão et al. (2004).

Os valores médios de composição das bactérias ruminais (Tabela 7) obtidos para MS e MO, de 80,44 e 72,87\%, respectivamente, foram próximos aos observados por Rennó (2003), de 80,74 e 74,61\%, e por Valadares Filho et al. (1990b), de 82,35 e $71,43 \%$, respectivamente. Leão et al. (2004) encontraram média maior para MS $(89,5 \%)$ e menor para MO $(71,5 \%)$. Os valores de MO foram ainda inferiores aos relatados por Valadares Filho (1995), de 89,20\%, em revisão de literatura nacional. Menores valores de MO podem decorrer do alto teor de cinzas nas bactérias, devido à contaminação com solução salina durante o seu processo de isolamento, como relatado em alguns trabalhos (Leão,

Tabela 5 - Recuperação dos indicadores e coeficientes de digestibilidade total (\%) dos nutrientes estimados por diferentes métodos

\begin{tabular}{lcccc}
\hline Item $^{1}$ & \multicolumn{3}{c}{ Método } \\
\cline { 2 - 5 } Variável $^{2}$ & Coleta total & FDNi & FDAi & Valor $\mathrm{P}^{3}$ \\
\hline Recuperação (\%) & - & $91,58 \mathrm{~b}$ & $103,22 \mathrm{a}$ & 0,0010 \\
Excreção fecal & $1,544 \mathrm{~b}$ & $1,708 \mathrm{a}$ & $1,526 \mathrm{~b}$ & 0,0039 \\
Digestibilidade total MS & $59,39 \mathrm{a}$ & $55,51 \mathrm{~b}$ & $60,43 \mathrm{a}$ & 0,0023 \\
Digestibilidade total MO & $61,18 \mathrm{a}$ & $57,46 \mathrm{~b}$ & $62,19 \mathrm{a}$ & 0,0023 \\
Digestibilidade total PB & $70,13 \mathrm{a}$ & $67,13 \mathrm{~b}$ & $70,80 \mathrm{a}$ & 0,0018 \\
Digestibilidade total EE & $60,11 \mathrm{a}$ & $56,20 \mathrm{~b}$ & $61,09 \mathrm{a}$ & 0,0022 \\
Digestibilidade totalCT & $59,34 \mathrm{a}$ & $55,47 \mathrm{~b}$ & $60,42 \mathrm{a}$ & 0,0024 \\
Digestibilidade total FDNcp & $58,54 \mathrm{a}$ & $54,77 \mathrm{~b}$ & $59,82 \mathrm{a}$ & 5,3 \\
Digestibilidade total CNF & $61,82 \mathrm{a}$ & $57,09 \mathrm{~b}$ & $61,98 \mathrm{a}$ & 5,0033 \\
\hline
\end{tabular}

${ }^{1} \mathrm{FDNi}=$ fibra em detergente neutro indigestível; FDAi = fibra em detergente ácido indigestível; CT = carboidratos totais; CNF = carboidratos não-fibrosos FDNcp = fibra em detergente ácido corrigida para cinzas e proteína.

2 Médias, na linha, seguidas por letras diferentes, são diferentes $(P<0,05)$ pelo teste Tukey.

3 Nível descritivo de probabilidade para o erro tipo I associado à hipótese de nulidade relacionada à ausência de diferença entre métodos. 
Tabela 6 - Coeficientes de digestibilidade parcial dos nutrientes da dieta experimental estimados com diferentes indicadores

\begin{tabular}{lrrrr}
\hline \multicolumn{5}{c}{ Indicador } \\
\cline { 2 - 3 } Nutriente $^{1}$ & FDNi & FDAi & Valor $\mathrm{P}^{2}$ & CV $(\%)$ \\
\hline \multicolumn{4}{c}{ Digestibilidade ruminal $^{3}$} \\
MS & 51,16 & 60,12 & 0,1286 & 22,8 \\
MO & 69,93 & 74,85 & 0,2419 & 12,8 \\
PB & 23,81 & 31,98 & 0,0262 & 26,4 \\
EE & $-19,36$ & $-7,92$ & 0,0466 & 86,7 \\
C T & 81,80 & 84,74 & 0,4533 & 10,6 \\
FDNcp & 90,78 & 91,80 & 0,7819 & 9,2 \\
CNF & 18,84 & 36,19 & 0,0870 & 77,9 \\
\hline \multicolumn{5}{c}{ Digestibilidade intestinal } \\
& 35,46 & 37,37 & 0,4509 & \\
\hline MS & 28,77 & 29,04 & 0,5892 & 24,7 \\
MO & 55,99 & 56,87 & 0,6200 & 7,17 \\
PB & 60,75 & 61,39 & 0,6429 & 5,21 \\
EE & 18,53 & 20,15 & 0,5030 & 46,0 \\
C T & 8,36 & 9,90 & 0,6989 & 99,6 \\
FDNcp & 49,28 & 53,29 & 0,8298 & 45,7 \\
CNF & &
\end{tabular}

$\mathrm{CT}$ = carboidratos totais; FDNcp = fibra em detergente ácido corrigida para cinzas e proteína; $\mathrm{CNF}$ = carboidratos não-fibrosos.

${ }_{1}^{1} \mathrm{FDNi}=$ fibra em detergente neutro indigestível; FDAi = fibra em detergente ácido indigestível.

2 Nível descritivo de probabilidade para o erro tipo I associado à hipótese de nulidade relacionada à ausência de diferença entre indicadores.

$3 \%$ da quantidade que chegou a cada local.

Tabela 7 - Composição das bactérias ruminais

\begin{tabular}{lcc}
\hline Item $^{1}$ & Média & Erro-padrão \\
\hline $\mathrm{MS}^{2}$ & 80,44 & 0,56 \\
$\mathrm{MO}^{3}$ & 72,87 & 1,26 \\
$\mathrm{NT}^{3}$ & 7,48 & 0,11 \\
$\mathrm{~N}_{\text {RNA }}$ & 2,40 & 0,08
\end{tabular}

${ }^{1} \mathrm{NT}=$ compostos nitrogenados totais; N-RNA = compostos nitrogenados do ácido ribonucléico.

$2 \%$.

$3 \% \mathrm{MS}$.

2002; Rennó, 2003). O valor de NT observado nesta pesquisa $(7,48 \%)$ está próximo dos mencionados por Leão (2002) e Rennó (2003) de 6,86 e 6,88\%, respectivamente.

Avaliando-se os resultados da produção e eficiência de síntese microbiana obtidos em coletas de amostras no omaso, em função de diferentes indicadores (Tabela 8), infere-se que, embora não tenha havido diferença significativa entre a produção e a eficiência de síntese microbiana estimadas com os diferentes indicadores $(\mathrm{P}>0,05)$, os valores obtidos com FDNi foram numericamente superiores. Vale ressaltar, como visto anteriormente (Tabela 5), que a utilização deste último indicador superestimou a produção fecal e subestimou a digestibilidade total quando comparado à coleta total de fezes, ao passo que os valores obtidos com a FDAi foram similares à coleta total.
As eficiências de síntese microbiana dos compostos nitrogenados expressas em relação ao consumo de matéria orgânica e carboidratos totais degradados no rúmen (MODR e CTDR, respectivamente) foram inferiores às observadas por Leão (2002) e próximos às de Rennó (2003) e Reynal et al. (2003).

A proporção de alantoína e ácido úrico estimada apresentou composição média próxima à citada por Verbic et al. (1990), de 85\% de alantoína (Tabela 9). A proporção estimada foi de $81,92 \%$ de alantoína, inferior à estimada por Leão (2002), de 87,90\%, e Rennó (2003), de 91,93\%. A concentração de alantoína foi aproximadamente igual à observada por Rennó et al. (2000), no entanto a quantidade de ácido úrico foi inferior neste experimento.

Tabela 8 - Produção e eficiência de síntese microbiana estimadas com diferentes indicadores

\begin{tabular}{|c|c|c|c|c|}
\hline \multirow[b]{2}{*}{ Item } & \multicolumn{2}{|c|}{ Indicador } & \multirow[b]{2}{*}{ Valor $\mathrm{P}^{2}$} & \multirow[b]{2}{*}{ CV (\%) } \\
\hline & FDNi & FDAi & & \\
\hline & \multicolumn{2}{|c|}{ Produção microbiana 3} & & \\
\hline gNmic/dia & 44,92 & 41,78 & 0,1415 & 10,0 \\
\hline gMSmic/dia & 603,35 & 562,32 & 0,1401 & 9,7 \\
\hline \multirow[t]{2}{*}{ gMOmic/dia } & 444,04 & 412,97 & 0,1387 & 10,0 \\
\hline & \multicolumn{3}{|c|}{ Eficiência microbiana ${ }^{4}$} & \\
\hline $\begin{array}{l}\text { gNmic/ } \\
\text { kgMODR }\end{array}$ & 18,16 & 15,80 & 0,2339 & 24,3 \\
\hline $\begin{array}{l}\text { gNmic/ } \\
\text { kgCTDR }\end{array}$ & 19,22 & 17,20 & 0,2777 & 21,5 \\
\hline $\begin{array}{l}\text { gNmic/ } \\
\text { kgMOFR }^{5}\end{array}$ & 15,04 & 10,64 & 0,1732 & 51,8 \\
\hline $\begin{array}{l}\text { gMSmic/ } \\
\text { kgCTDR }\end{array}$ & 255,40 & 229,93 & 0,2889 & 20,8 \\
\hline
\end{tabular}

${ }^{1} \mathrm{FDNi}=$ fibra em detergente neutro indigestível; $\mathrm{FDAi}=$ fibra em detergente ácido indigestível.

2 Nível descritivo de probabilidade para o erro tipo I associado à hipótese de nulidade relacionada à ausência de diferença entre indicadores.

${ }^{3} \mathrm{Nmic}=$ compostos nitrogenados microbianos, $\mathrm{MSmic}=$ matéria seca microbiana e MOmic = matéria orgânica microbiana.

${ }^{4} \mathrm{Nmic} / \mathrm{MODR}=$ quantidade de $\mathrm{Nmic}$ expressos em relação à matéria orgânica degradada no rúmen, Nmic/CTDR = quantidade de Nmic expressos em relação aos carboidratos totais degradados no rúmen $\mathrm{Nmic} / \mathrm{MOFR}$ = quantidade de Nmic expressos em relação matéria orgânica fermentada no rúmen; MSmic/CTDR = quantidade de MSmic expresso em relação aos carboidratos degradados no rúmen.

${ }^{5}$ MOFR = matéria orgânica consumida menos a diferença entre o fluxo omasal de matéria orgânica e o fluxo omasal de MOmic.

Tabela 9 - Estimativa do volume e excreções de derivados de purinas urinárias e purinas absorvidas

\begin{tabular}{lrc}
\hline Item $^{1}$ & Média & Erro-padrão \\
\hline VU (kg/dia) & 4,65 & 0,70 \\
ALA (mmol/dia) & 74,00 & 22,27 \\
AU (mmol/dia) & 16,33 & 6,06 \\
Pabs (mmol/dia) & 106,27 & 23,82 \\
\hline
\end{tabular}

${ }^{1} \mathrm{VU}=$ volume urinário, $\mathrm{ALA}=$ de alantoína, $\mathrm{AU}=$ excreções urinárias de ácido úrico e Pabs = derivados de purinas (ALA + AU) absorvidos. 
As produções de Nmic diário estimadas pelo fluxo omasal com FDNi ou FDAi não diferiram $(\mathrm{P}>0,05)$ entre si, mas diferiram $(\mathrm{P}<0,05)$ das estimadas com os derivados de purinas em coleta spot de urina (Tabela 10). Os valores obtidos com as bases de purinas foram superiores aos estimados pelos derivados de purinas. Assim, se forem utilizados os derivados de purinas para estimar a produção microbiana, em vez das bases de purinas, os valores serão subestimados. Essa observação difere de resultados obtidos por outros pesquisadores (Rennó et al., 2000; Leão, 2002; Chizzotti et al., 2004), que não encontraram diferenças significativas ao compararem os valores obtidos entre os bases e os derivados de purinas.

As condições no rúmen foram favoráveis à produção microbiana com valores de $\mathrm{pH}$ variando de 6,7 a 6,9, estando dentro da faixa para o máximo crescimento microbiano citado por Hoover \& Stokes (1991), de 5,5 a 7,1 (Figura 1a).

Tabela 10 - Produção microbiana de compostos nitrogenados estimados com diferentes métodos de indicadores

\begin{tabular}{lcccc}
\hline Item & \multicolumn{2}{c}{${\text { Base } \text { purina }^{1}}$} & $\begin{array}{c}\text { Derivado } \\
\text { de purinas }\end{array}$ & CV (\%) \\
\cline { 2 - 3 } & FDNi & FDAi & & \\
\hline $\mathrm{gNmic}^{2} \mathrm{dia}^{3,4}$ & $44,92 \mathrm{a}$ & $41,78 \mathrm{a}$ & $22,93 \mathrm{~b}$ & 31,22 \\
\hline
\end{tabular}

${ }^{1} \mathrm{FDNi}=$ fibra em detergente neutro; FDAi = fibra em detergente neutro indigestível.

${ }^{2} \mathrm{Nmic}=$ compostos nitrogenados microbianos

${ }^{3}$ Médias seguidas por letras diferentes são diferentes $(P<0,05)$ pelo teste Tukey.

a

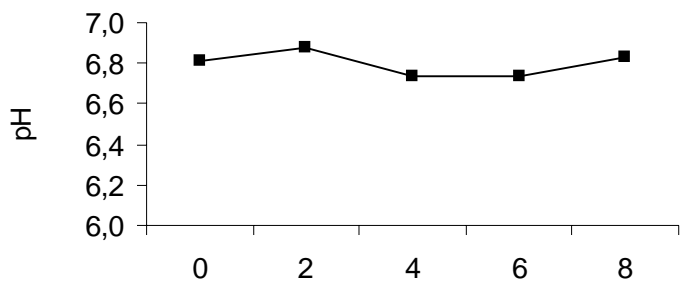

Horas após alimentação (h)

b

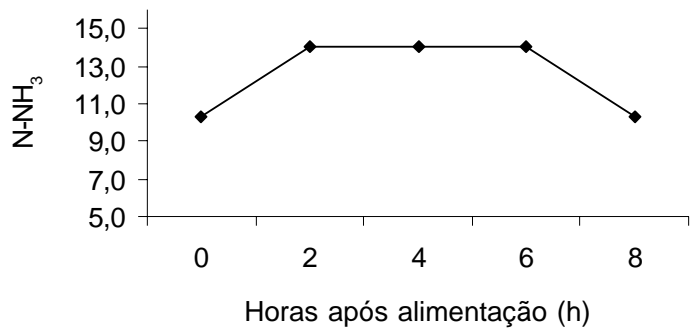

Figura 1 - Valores de pH (a) e nitrogênio amoniacal $\left(\mathrm{N}-\mathrm{NH}_{3}\right)(b)$ do líquido ruminal, em função dos tempos de coleta pós-alimentação.
Os valores de $\mathrm{N}-\mathrm{NH}_{3}$ obtidos nesta pesquisa variaram de 10,3 a $14,1 \mathrm{mg} / \mathrm{dL}$, ficando acima de $5 \mathrm{mg} / \mathrm{dL}$ de líquido ruminal sugerido por Satter \& Slyter (1974) como mínimo para a produção microbiana. Os maiores valores de $\mathrm{N}-\mathrm{NH}_{3}$ obtidos foram atingidos duas horas após a alimentação (Figura 1b).

\section{Conclusões}

A FDAi apresenta melhor recuperação e produz estimativas similares para a excreção fecal e a digestibilidade total quando comparada à coleta total de fezes.

As estimativas da produção microbiana via quantificação de derivados de purinas em amostras spot de urina não se demonstraram similares às obtidas por procedimentos invasivos via fluxo de matéria microbiana omasal, necessitando de mais pesquisas.

\section{Literatura Citada}

ASSOCIATION OF OFFICIAL ANALYTICAL CHEMISTS AOAC. Official methods of analysis. 15.ed. Virginia: 1990 V.1, 1117p.

BERCHIELLI, T.T.; RODRIGUEZ, N.M.; OSÓRIO NETO, E. et al. Comparação de indicadores de fase sólida para medir fluxo de matéria seca e matéria orgânica no duodeno. Arquivo Brasileiro de Veterinária e Zootecnia, v.50, n.2, p.147152,1998 .

BERCHIELLI, T.T.; ANDRADE, P.; FURLAN, C.L. Avaliação de indicadores internos em ensaios de digestibilidade. Revista Brasileira de Zootecnia, v.29, n.3, p.830-833, 2000.

BRODERICK, G.A.; MERCHEN, N.R. Markers for quantifying microbial protein synthesis in the rumen. Journal of Dairy Science, v.75, n.9, p.2618-2632, 1992.

CABRAL, L.S. Avaliação de alimentos para ruminantes pro intermédio de métodos in vivo $e$ in vitro. Viçosa, MG: Universidade Federal de Viçosa, 2002. 133p. Tese (Doutorado em Zootecnia) - Universidade Federal de Viçosa, 2002.

CECAVA, M.J.; MERCHEN, N.R.; GAY, L.C. et al. Composition of ruminal bacteria harvested from steers as influenced by dietary energy level, feeding frequency and isolation techniques. Journal of Dairy Science, v.73, n.9, p.24802488, 1990.

CHEN, X.; GOMES, M.J. Estimation of microbial protein supply to sheep and cattle based on urinary excretion of purine derivatives: an overview of the technical details. Bucksburn: Rowett Research Institute, 1992. 21p. (Occasional publication).

CHIZZOTTI, M.L.; VALADARES FILHO, S.C.; VALADARES, R.F.D. et al. Excreção de creatinina em novilhos e novilhas. In: REUNIÃO ANUAL DA SOCIEDADE BRASILEIRA DE ZOOTECnIA, 41., 2004, Campo Grande. Anais... Campo Grande: 2004. (CD-ROM).

CLARK, J.H.; KLUSMEYER, T.H.; CAMERON, M.R. Microbial protein synthesis and flows of nitrogen fractions to the duodenum of dairy cows. Journal of Dairy Science, v.75, n. 8, p.2304-2323, 1992.

COCHRAN, R.C.; ADAMS, D.C.; WALLACE, J.D. et al. Predicting digestibility of different diets with internal markers: evaluation of four potential markers. Journal of Animal Science, v.63, n.5, p.1476-1483, 1986. 
FREITAS, D.; BERCHIELLI, T.T.; SILVEIRA, R.N. Consumo e digestibilidade aparente total e parcial de rações com cana-deaçúcar e raspa de mandioca ensilados com polpa cítrica. Revista Brasileira de Zootecnia, v.31, n.3, p.1531-1542, 2002. (suplemento)

FUJIHARA, T.; ORSKOV, E.R.; REEDS, P.J. et al. The effect of protein infusion on urinary excretion of purine derivatives in ruminants nourished by intragastric nutrition. Journal of Agricultural Science, v.77, n.8, p.7-12, 1987.

GIESECKE, D.; EHRENTREICH, L.; STANGASSINGER, M. Mammary and renal excretion of purine metabolites in relation to energy intake and milk yield in dairy cows. Journal of Dairy Science, v.77, n.8, p.2376-2381, 1994.

HOOVER, W.H.; STOKES, S.R. Balancing carbohydrates and proteins for optimum rumen microbial yield. Journal of Dairy Science, v.74, n.10, p.3630-3644, 1991.

ÍTAVO, L.C.V.; SILVA, F.F.; FERREIRA, C.C.B. et al. Comparação de indicadores e metodologia de coleta para estimativas de produção fecal e fluxo da digesta em bovinos. Revista Brasileira de Zootecnia, v.31, n.4, p.1833-1839, 2002.

LEÃO, M.I. Metodologias de coletas de digestas omasal e abomasal em novilhos submetidos a três níveis de ingestão: consumo, digestibilidade e produção microbiana. Belo Horizonte: Universidade Federal de Minas Gerais, 2002. 57p. Tese (Doutorado) - Universidade Federal de Minas Gerais, 2002.

LEÃO, M.I.; VALADARES FILHO, S.C.; RENNÓ, L.N. et al. Consumos e digestibilidades totais e parciais de matéria seca, matéria orgânica, proteína bruta e extrato etéreo em novilhos submetidos a três níveis de ingestão e duas metodologias de coleta de digestas abomasal e omasal. Revista Brasileira de Zootecnia, v.33, n.6, p.1604-1615, 2004

LEÃO, M.I.; VALADARES FILHO, S.C.; RENNÓ, L.N. et al. Consumos e digestibilidades totais e parciais de carboidratos totais, fibra em detergente neutro e carboidratos não-fibrosos em novilhos submetidos a três níveis de ingestão e duas metodologias de coleta de digestas abomasal e omasal. Revista Brasileira de Zootecnia, v.34, n.2, p.670-678, 2005.

LIPPKE, H.; ELLIS, W.C.; JACOBS, F. Recovery of indigestible fiber from feces of sheep and cattle on forage diets. Journal of Dairy Science, v.69, n.2, p.403-412, 1986.

MERTENS, D.R. Regulation of forage intake. In: FAHEY JR., G.C. (ED.) Forage quality, evaluation and utilization. Madison: American Society of Agronomy, 1994. p.450-493.

MERCHEN, R.N.; ELIZALDE, J.C.; DRACKLEY, J.K. Current perspective on assessing site of digestion in ruminants. Journal of Dairy Science, v.75, n.8, p.2223-223, 1997.

OLIVEIRA, A.S.; VALADARES, R.F.D.; VALADARES FILHO, S.C. et al. Produção de proteína microbiana e estimativas das excreções de derivados de purinas e de uréia em vacas lactantes alimentadas com rações contendo diferentes níveis de compostos nitrogenados não protéicos. Revista Brasileira de Zootecnia, v.30, n.5, p.1621-1629, 2001.

PELL, A.N.; SCHOFIELD, P. Computerized monitoring of gas production to measure forage digestion in vitro. Journal of Dairy Science, v.76, n.4, p.1063-1073, 1993.

PEREIRA, M.L.A. Proteína nas dietas de vacas nos terços inicial e médio da lactação. Viçosa, MG: Universidade Federal de Viçosa, 2003. 105p. Tese (Doutorado em Zootecnia) Universidade Federal de Viçosa, 2003.

RENNÓ, L.N. Consumo, digestibilidade total e parcial, produção microbiana, parâmetros ruminais e excreções de uréia e creatinina em novilhos alimentados com dietas contendo quatro níveis de uréia ou dois níveis de proteína. Viçosa, MG: Universidade Federal de Viçosa, 2003. 105p. Tese (Doutorado em Zootecnia) - Universidade Federal de Viçosa, 2003.

RENNÓ, L.N.; VALADARES, R.F.D.; LEÃO, M.I. et al. Estimativa da produção de proteína microbiana pelos derivados de purina na urina em novilhos. Revista Brasileira de Zootecnia, v.29, n. 4 , p.1223-1234, 2000 .
RENNÓ, L.N.; VALADARES FILHO, S.C.; VALADARES, R.F.D et al. Níveis de proteína na ração de novilhos de quatro grupos genéticos: estimativa da produção de proteína microbiana por intermédio dos derivados de purinas na urina. In: REUNIÃO ANUAL DA SOCIEDADE BRASILEIRA DE ZOOTECNIA, 40. 2003, Santa Maria. Anais... Santa Maria: Sociedade Brasileira de Zootecnia, 2003. (CD-ROM).

RENNÓ, L.N.; VALADARES FILHO, S.C.; PAULINO, M.F. et al. Consumo por novilhos de quatro grupos genéticos alimentados com dietas contendo níveis crescentes de uréia. In: REUNIÃO ANUAL DA SOCIEDADE BRASILEIRA DE ZOOTECNIA, 41. 2004, Campo Grande. Anais... Campo Grande: Sociedade Brasileira de Zootecnia, 2004a. (CD-ROM).

RENNÓ, L.N.; VALADARES FILHO, S.C.; DINIZ, R.F. et al. Níveis de proteína na ração de novilhos de quatro grupos genéticos: digestibilidade aparente parcial. In: REUNIÃO ANUAL DA SOCIEDADE BRASILEIRA DE ZOOTECNIA, 41., 2004b, Campo Grande. Anais... Campo Grande: Sociedade Brasileira de Zootecnia, 2004b. (CD-ROM).

REYNAL, S.M.; BRODERICK, G.A.; AHVENJÄRVI, S. et al. Effect of feeding protein supplements of differing degradability on omasal flow of microbial and undegraded protein. Journal of Dairy Science, v.86, n.4, p.1292-1305, 2003.

SALIBA, E.O.S.; RODRIGUEZ, N.M.; GONCCALVES, L.C. et al. Estudo comparativo da lignina isolada da palha de milho, com outros indicadores em ensaio de digestibilidade aparente. In: REUNIÃO ANUAL DA SOCIEDADE BRASILEIRA DE ZOOTECNIA, 36., 1999, Porto Alegre. Anais... São Paulo: Sociedade Brasileira de Zootecnia, 1999. (CD-ROM).

STATISTICAL ANALYSIS SYSTEM - SAS. SAS/STAT user's guide (Release 8.0). Cary: 1999. (CD-ROM).

SATTER, L.D.; SLYTER, L.L. Effect of ammonia concentration on rumen microbial protein production in vitro. British Journal of Nutrition, v.32, n.2, p.199-208, 1974.

SILVA, D.J.; QUEIROZ, A.C. Análises de alimentos: métodos químicos e biológicos. 3.ed. Viçosa, MG: Editora UFV, 2002. $235 \mathrm{p}$.

SILVA, R.M.N.; VALADARES, R.F.D.; VALADARES FILHO, S C. et al. Uréia para vacas em lactação. 2. Estimativas do volume urinário da produção microbiana e da excreção de uréia. Revista Brasileira de Zootecnia, v.30, n.6, p.1948-1957, 2001.

SUSMEL, P.; STEFANON, B.; PLAZZOTTA, E. et al. The effect of energy and protein intake on the excretion of purine derivatives. Journal of Dairy Science, v.123, p.257-266, 1994.

TITGEMEYER, E.C. Design and interpretation of nutrient digestion studies. Journal of Animal Science, v.75, n.8, p.2235-2247, 1997

USHIDA, K.; LASSALAS, B.; JOUANY, J.O. Determination of assay parameters for RNA analysis in bacterial and duodenal samples by spectrophotometry influence of samples treatment and preservation. Reproduction and Nutrition Development, v. 25, n.6, p.1037-1046, 1985

VALADARES, R.F.D.; VALADARES FILHO, S.C.; GONCCALVES, L.C. et al. Níveis de proteína em dietas de bovinos.4 . Concentrações de amônia ruminal e uréia plasmática e excreções de uréia e creatinina. Revista Brasileira de Zootecnia, v.26, n.6, p.1270-1278, 1997 .

VALADARES, R.F.D.; BRODERICK, G.; VALADARES FILHO, S.C. et al. Effect of replacing alfafa of silage with high moisture corn on ruminal protein synthesis estimated from excretion of total purine derivatives. Journal of Dairy Science, v.82, n.12, p.2686-2696, 1999.

VALADARES FILHO, S.C. Digestão total e parcial da matéria seca e carboidratos em bovinos e bubalinos. Viçosa, MG: Universidade Federal de Viçosa, 1985. 147p. Tese (Doutorado em Zootecnia) - Universidade Federal de Viçosa, 1985. 
VALADARES FILHO, S.C. Eficiência de síntese de proteína microbiana, degradação ruminal e digestibilidade intestinal da proteína bruta, em bovinos. In: SIMPÓSIO INTERNATIONAL SOBRE EXIGÊNCIAS NUTRICIONAIS DE RUMINANTES, 1995, Viçosa, MG. Anais... Viçosa, MG: Universidade Federal de Viçosa, 1995. p.355-388.

VALADARES FILHO, S.C.; SILVA, J.F.C.; LEÃO, M.I. et al. Eficiência de síntese microbiana em novilhos holandeses, nelores e búfalos mestiços. Revista da Sociedade Brasileira de Zootecnia, v.19, n.5, p.416-423, 1990a.

VALADARES FILHO, S.C.; COELHO DA SILVA, J.F.; SANTANNA, R. et al. Composição de bactérias ruminais e absorção de aminoácidos microbianos no intestino delgado de novilhos holandeses, nelores e búfalos mestiços. Revista da Sociedade Brasileira de Zootecnia, v.19, n.5, p.431-440, 1990 b.
VALADARES FILHO, S.C.; VALADARES, R.F.D. Recentes avanços em proteína na nutrição de vacas leiteiras. In: SIMPÓSIO DE BOVINOCUlTURA DE LEITE, 2., 2001, Lavras. Palestras... Lavras: Universidade Federal de Lavras, 2001. (CD-ROM).

VIEIRA, P.F. Efeito do formaldeído na proteção de proteínas e lipídeos em rações para ruminantes. Viçosa, MG: Universidade Federal de Viçosa, 1980. 98p. Tese (Doutorado em Zootecnia) - Universidade Federal de Viçosa, 1980.

VERBIC, J.; CHEN, X.B.; MACLEOD, N.A. et al. Excretion of purine derivatives by ruminants. Effect of microbial nucleic acid infusion on purine derivative excretion by steers. The Journal of Agricultural Science, v.114, n.3, p.243-248, 1990.

ZEOULA, L.M.; PRADO, I.N.; DIAN, P.H.M. et al. Recuperação fecal de indicadores internos avaliados em ruminantes. Revista Brasileira de Zootecnia, v.31, n.4, p.1865-1874, 2002. 